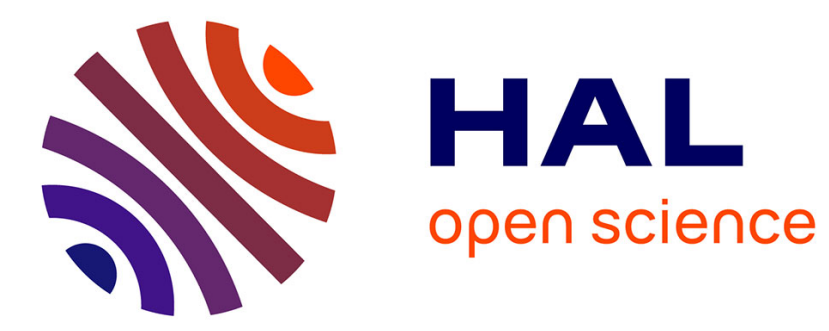

\title{
Damage Detection and Deteriorating Structural Systems
}

\author{
Lijia Long, Sebastian Thöns, Michael Döhler
}

\section{To cite this version:}

Lijia Long, Sebastian Thöns, Michael Döhler. Damage Detection and Deteriorating Structural Systems. IWSHM - 11th International Workshop on Structural Health Monitoring, Sep 2017, Stanford, United States. 10.12783/shm2017/13997 . hal-01589545

\section{HAL Id: hal-01589545 \\ https://hal.inria.fr/hal-01589545}

Submitted on 18 Sep 2017

HAL is a multi-disciplinary open access archive for the deposit and dissemination of scientific research documents, whether they are published or not. The documents may come from teaching and research institutions in France or abroad, or from public or private research centers.
L'archive ouverte pluridisciplinaire HAL, est destinée au dépôt et à la diffusion de documents scientifiques de niveau recherche, publiés ou non, émanant des établissements d'enseignement et de recherche français ou étrangers, des laboratoires publics ou privés. 
Title: Damage Detection and Deteriorating Structural Systems

\author{
Authors : Lijia Long ${ }^{1,2}$ \\ Sebastian Thöns ${ }^{1,2}$ \\ Michael Döhler ${ }^{1,3}$
}




\begin{abstract}
This paper addresses the quantification of the value of damage detection system and algorithm information on the basis of Value of Information (VoI) analysis to enhance the benefit of damage detection information by providing the basis for its optimization before it is performed and implemented. The approach of the quantification the value of damage detection information builds upon the Bayesian decision theory facilitating the utilization of damage detection performance models, which describe the information and its precision on structural system level, facilitating actions to ensure the structural integrity and facilitating to describe the structural system performance and its functionality throughout the service life. The structural system performance is described with its functionality, its deterioration and its behavior under extreme loading. The structural system reliability given the damage detection information is determined utilizing Bayesian updating. The damage detection performance is described with the probability of indication for different component and system damage states taking into account type 1 and type 2 errors. The value of damage detection information is then calculated as the difference between the expected benefits and risks utilizing the damage detection information or not. With an application example of the developed approach based on a deteriorating Pratt truss system, the value of damage detection information is determined, demonstrating the potential of risk reduction and expected cost reduction.
\end{abstract}

Key words: value of information, damage detection, structural reliability and risks, reliability updating

\title{
INTRODUCTION
}

Identifying efficient structural health monitoring (SHM) strategies for performance monitoring and improving the decision basis for optimal life-cycle management of the

\footnotetext{
${ }^{1}$ Department 7: Safety of structures, Federal Institute for Materials Research and Testing (BAM), 12205 Berlin, Germany, lijia.long@bam.de

2 Deartment of Civil Engineering, Technical University of Denmark, 2800 Lyngby, Denmark, sebt@byg.dtu.dk

3 Inria, I4S, 35042 Rennes, France, and IFSTTAR, COSYS, SII, Bouguenais, France, Michael.doehler@inria.fr
} 
structures are of great interest for researchers. It is essential to know how system reliability will be influenced by the detected damage from SHM and estimate the economic benefit of a monitoring system for any detectable events.

Döhler et.al. [1] have introduced an approach for the damage detection system (DDS) performance modelling which applies to structural systems and contains a strategy to overcome the high computational efforts for the pre-determination of the damage detection system reliability. Based on their methodology, this paper addresses quantifying the value of DDS information and optimizing system performance. This paper firstly introduces the theory of the quantification of the value of damage detection information. Secondly a structural system modeling including structural system performance and generic system deterioration model is introduced. Then the damage detection system performance is described and the structural system reliability is updated with damage detection information. Finally, an example on how to apply the developed approach on a deteriorating Pratt truss system and how to determine the value of DDS information is presented.

\section{QUANTIFICATION OF VALUE OF INFORMATION}

The Value of Information (VoI) theory is developed by Raiffa and Schlaifer in [2]. Analysis of VoI is rooted in Bayesian updating and utility-based decision theory, which having a certain format to quantify the utility increase of unknown information. Pozzi et.al. [3] and Thöns [4] pioneers the early researches for quantification of value of Structural Health Monitoring information. A more comprehensive formulation of the approach is presented in [5] and [6]. In general, the value or utility is the combination of the certain SHM strategy, SHM outcome, action and system state resulting in $u(e, z, a, \theta)$. The expected $\mathrm{VoI}$ can be found as the difference between the maximum utility $u_{1}^{*}$ obtained in (pre-) posterior analysis and the maximum utility $u_{0}^{*}$ obtained using only prior information, which means that a value to a piece of information can be assigned as the difference between expected utilities of the optimum decisions with and without that information.

$$
V o I=u_{1}^{*}-u_{0}^{*}
$$

\section{STRUCTURAL SYSTEM MODELING}

For any structural model, whether the failure occurs or not depends on roughly two groups of factors: external actions of loads and actions on structures denoting with $S$, and internal resistances of structure such as material properties and geometrical characteristics of elements, corresponding with $R$. The structural system resistance is continuously reduced by the development of deterioration over time. When load $S$ exceeds resistance $R$, the failures will occur.Let $g_{i}(\mathbf{X}, \mathbf{D})$ denote the limit state function, such that $g_{i}(\mathbf{X}, \mathbf{D}) \leq 0$ represents the condition of failure of the structure or component. The probability of failure can be described as:

$$
P\left(F_{S}\right)=P\left(g_{i}(\mathbf{X}, \mathbf{D}) \leq 0\right)=\int_{\Omega_{F_{s}}} f_{F_{s}}(\mathbf{X}, \mathbf{D}) \mathrm{d} \mathbf{D} \mathrm{d} \mathbf{X}
$$


The vector of the system performance random variables $\mathbf{X}$ then comprises the resistance model uncertainties $M_{R}$, the time dependent component resistances $R_{i}(t)$, the loading model uncertainty $M_{s}$ and the component loading $S$. The vector of the system degradation random variables $\mathbf{D}$ contains the collection of the deterioration states for $n$ components.

$$
\begin{aligned}
& \mathbf{X}=\left[M_{R, i}, R_{i}(t), M_{s}, S\right]^{T} \\
& \mathbf{D}=\left[D_{1}(t) \ldots D_{n}(t)\right]^{T}
\end{aligned}
$$

\section{Generic system deterioration model}

Qin et.al. [7] described a general and generic deterioration formulation, which could be regarded as an accumulation process with time, $\Delta_{D, i}$ is the annual deterioration increments.

$$
D_{i}(t)=\sum_{i=1}^{t} \Delta_{D, i}
$$

Structural components can be linked together in series or in parallel or in a combination of these two. Coupling the deterioration model and the structural system performance, the probability of system failure can be written as:

$$
P\left(F_{S}\right)=P\left(\bigcap_{i=1}^{n_{i}} \bigcup\left(M_{R, i} R_{i, 0}\left(1-\sum_{i=1}^{t} \Delta_{D, i}\right)-M_{s} S\right) \leq 0\right)
$$

\section{UPDATING THE STRUCTURAL SYSTEM RELIABILITY WITH DAMAGE DE- TECTION INFORMATION}

The subspace-based damage detection method (SSDD see [8] )is considered as the algorithm that provides the damage detection information. Based on ambient vibration measurements from a (healthy) reference state and measurements from the current system, the SSDD technique computes a residual vector and a respective test statistic that compares both states. This test statistic is a random variable that is asymptotically $\chi^{2}$-distributed (when the measurement length is sufficiently long), having a central $\chi^{2}$ distribution in the reference state and a non-central $\chi^{2}$ distribution in the damaged state. Thanks to this property, the test statistic can be compared to a threshold for the indication of damage. This threshold is set up in the reference state for a desired type I error.

For a given system degradation $\mathrm{D}$, the probability of its indication with the SSDD technique is obtained as follows. Let any system degradation $\mathbf{D}$ be linked to changes $\left(\theta-\theta_{0}\right)$ in the set of structural parameters $\theta$ (e.g. element stiffness) of the monitored system, where $\theta_{0}$ corresponds to the (healthy) reference state. Then, the non-centrality parameter of the test statistic distribution is given by $\delta^{T} F \delta$, where $\delta=\sqrt{N}\left(\theta-\theta_{0}\right), N$ is the measurement length and $F$ is the Fisher information of $\theta$ contained in the computed residual vector [9]. Thus, the statistical distribution of the test statistic is known for a given system degradation (linked to $\mathbf{D}$ ) in the monitored system (linked to $F$ ). Based on the pdf of this distribution and the threshold set in the reference state, the probability 
of indication is obtained for any $\mathbf{D}$ [1], without the need of measurement data related to D. Actual measurement data (or its simulation) are only needed in the reference state $(\mathrm{D}=0)$ for the computation of $\mathrm{F}$, which depends on the properties of the monitored system such as the stochastic system properties (ambient excitation and measurement noise covariance) as well as sensor type and positions.

\section{Structural system performance updating}

The probability of detecting damage is expressed with Eq.(7) as referenced [10]. The probability density function for indication given damage is denoted here with $\rho(I \mid \mathbf{D})$.

$$
P(I)=\int_{\Omega_{\mathbf{D}}} \rho(I \mid \mathbf{D}) f_{D}(\mathbf{D}) \mathrm{d} \mathbf{D}
$$

The probability of no indication of detecting damage can be calculated by integrating in the region which is defined with the limit state function $g_{U} \leq 0$. The limit state function $g_{U}$ is defined as the difference between the probability of indication given damage $P(I \mid \mathbf{D})$ and a uniformly distributed random variable $u[1]$.

$$
\begin{aligned}
P(\bar{I})=1-P(I) & =\int_{\Omega_{\mathbf{D}}}(1-\rho(I \mid \mathbf{D})) f_{\mathbf{D}}(\mathbf{D}) \mathrm{d} \mathbf{D} \\
g_{U} & =P(I \mid \mathbf{D})-u
\end{aligned}
$$

The updated probability of failure if there is no indication of damage can be calculated as:

$$
P(F \mid \mathbf{D}, \bar{I})=\frac{P(\bar{I} \mid F, \mathbf{D}) P(F, \mathbf{D})}{P(\bar{I})}=\frac{P(F \mid \mathbf{D} \cap \bar{I})}{P(\bar{I})}=\frac{P\left(g \leq 0 \cap g_{u} \leq 0\right)}{P\left(g_{u} \leq 0\right)}
$$

\section{EXAMPLE}

We analyze a statically determinate Pratt truss. When it is under extreme loading, we set that the truss will collapse if the stresses in any member exceed the material strength. Due to this absence of redundancy, series system formulation is chosen. The probability of failure of the system $P\left(F_{S}\right)$ can be determined by taking basis in Eq.(6):

$$
P\left(F_{S}\right)=P\left(\bigcup_{i=1}^{n_{i}}\left(M_{R, i} R_{i, 0}\left(1-\sum_{i=1}^{t} \Delta_{D, i}\right)-M_{s} S\right) \leq 0\right)
$$

For series system, the system limit state function is equal to the minimum of all the component limit state function [11],i.e.:

$$
g(\mathbf{X}, \mathbf{D})=\min _{i=1} g_{i}(\mathbf{X}, \mathbf{D})
$$

The Pratt truss bridge is shown in Figure 1. The bridge description and the structural reliability model is summarized in Table $\mathrm{I}$. The mean of the resistance $R_{i, 0}$ is calibrated 


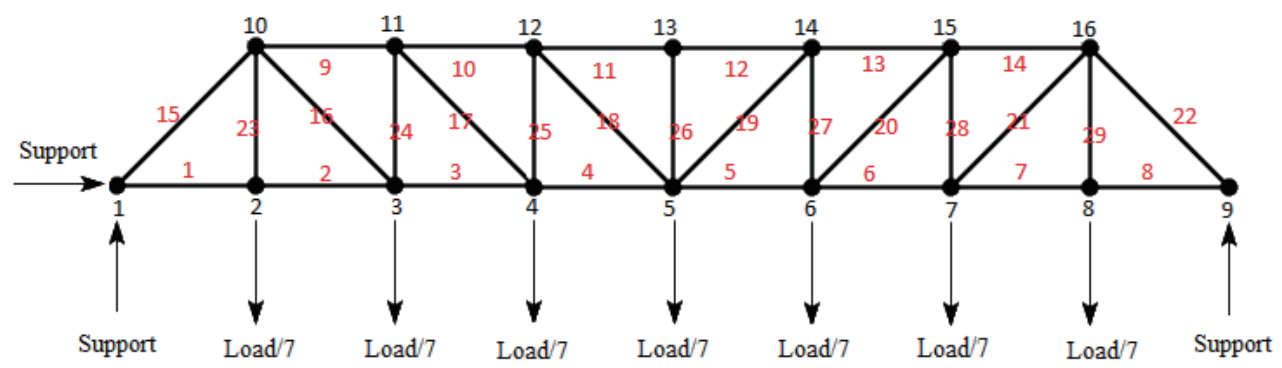

Figure 1. Pratt truss

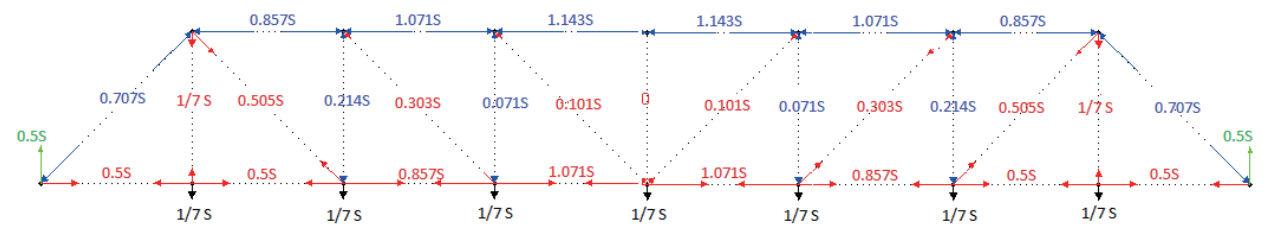

Figure 2. Local axial forces on the truss

to a probability of system failure of $10^{-6}$ disregarding any damage, considering the consequence of failure is large and relative cost of safety measure is small [12]. There is a probabilistic extreme loading $S$ applied vertically on the truss and it is evenly distributed on the lower nodes $2,3,4,5,6,7,8$ with $1 / 7 S$. The truss's beams have similar geometrical and probabilistic properties. The axial force on each beam element are calculated by methods of joints and shown on the Figure 2.Now we have all the local axial forces and probabilistic properties, we can set the limit state functions of each beam and calculate the probability of failure of each component (Figure 3). The probability of component/system failure is calculated by Monte Carlo Simulation.

The probability of truss failure will increase with time due to deterioration damage and it is shown in Figure 4. When the coefficient of correlation varies, the results indicate that with increase of coefficient of correlation of resistance, the probability of system failure will decrease.

TABLE I. DESCRIPTION OF THE BRIDGE

\begin{tabular}{|c|c|c|c|c|c|}
\hline Descriptions & Values & Description & Distribution & $\begin{array}{l}\text { Expected } \\
\text { value }\end{array}$ & $\begin{array}{l}\text { Standard } \\
\text { deviation }\end{array}$ \\
\hline $\begin{array}{l}\text { Number of } \\
\text { components }\end{array}$ & 29 & Loading of component $S_{i}$ & Weibull & 3.5 & 0.1 \\
\hline Number of nodes & 16 & $\begin{array}{l}\text { Resistance model } \\
\text { uncertainties } M_{R}\end{array}$ & Lognormal & 1.0 & 0.1 \\
\hline $\begin{array}{l}\text { Length of non- } \\
\text { diagonal element }\end{array}$ & $10 m$ & $\begin{array}{l}\text { Loading model } \\
\text { uncertainties } M_{s}\end{array}$ & Lognormal & 1.0 & 0.1 \\
\hline $\begin{array}{l}\text { Length of } \\
\text { diagonal element }\end{array}$ & $10 \sqrt{2} m$ & $\begin{array}{c}\text { Component resistance } \\
R_{(i, 0)}\end{array}$ & Lognormal & Calibrated & 0.1 \\
\hline Youngs modules E & $\begin{array}{l}14400 \\
N / m^{2}\end{array}$ & $\begin{array}{c}\text { Deterioration damage } \\
\Delta_{(D, i)}\end{array}$ & Normal & 0.007 & 0.003 \\
\hline Cross section A & $\begin{array}{c}10 / 144 \\
m^{2}\end{array}$ & $\begin{array}{l}\text { Coefficient of } \\
\text { correlation for resistances } \rho_{R}\end{array}$ & Deterministic & $0.1 / 0.5 / 0.9$ & \\
\hline Mass per component & 0.02 & $\begin{array}{l}\text { Coefficient of } \\
\text { correlation for damages } \rho_{D}\end{array}$ & Deterministic & $0.1 / 0.5 / 0.9$ & \\
\hline Damping ratio & $2 \%$ & & & & \\
\hline
\end{tabular}




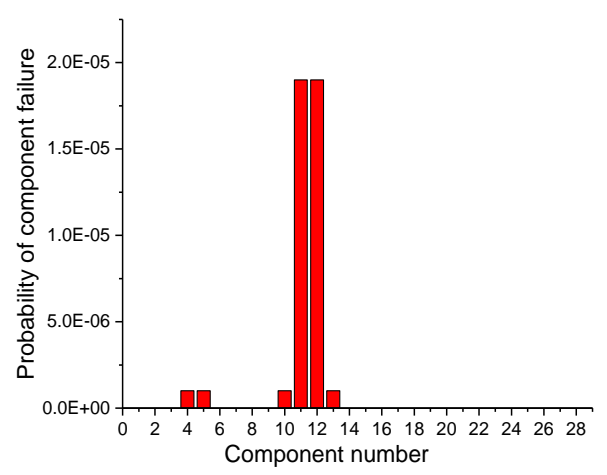

Figure 3. Probability of component failure $(t=10$ years $)$

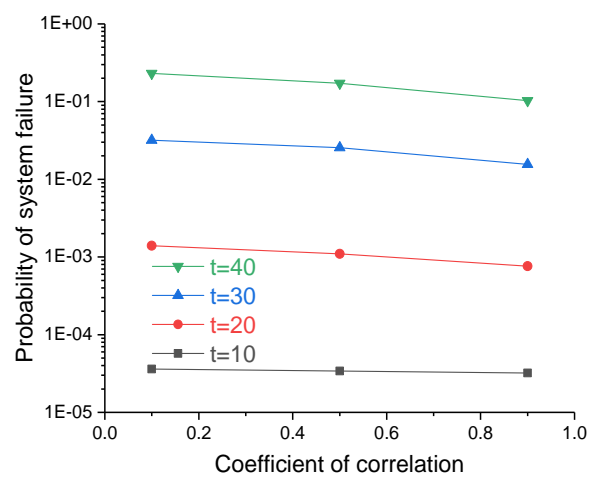

Figure 4. Probability of system failure with varied correlation coefficeint

\section{Damage detection information}

The damage detection system is modelled with acceleration sensors located in node $12,13,14$ of the truss in Y-direction recording the response using the SSDD algorithm. Based on the dynamic structural system model, a reference dataset of length $\mathrm{N}=10000$ at a sampling frequency of $50 \mathrm{~Hz}$ is simulated in the undamaged state. Assumed there are ambient excitation (white noise) at all DOFs, same amplitude everywhere and uncorrelated. Measurement noise has standard deviation at each sensor as 5\% percentage of standard deviation of signal and uncorrelated. Type I error for indication threshold is $1 \%$. The $P(I \mid \mathbf{D})$ are calculated based on the realization of damage $\mathbf{D}$ (stiffness loss from 0 to $10 \%$ in this paper). Considering human errors, $P(I \mid \mathbf{D})$ will be multiplied with 0.95 [1]. The probabilities of detecting damage $P(I)$ are calculated following Eq.10 during the Monte-Carlo simulation for each realizations of the damages $\mathbf{D}$.

\section{Quantification the value of DDS information}

Assume the truss bridge is under certain system state after 10 years in practical life. There are two scenarios for the truss: 1) Failure state: the truss is on the critical damage and it will collapse if it is over the critical state. There will be a cost $C_{F}$ related to the failure of the bridge. 2) Safe state: there is no damage and the bridge is safe, which will result annual benefit $B$. There are two options for the decision of actions: 1) Doing nothing, 2) Repair and there will be a cost for the repair $C_{R}$. When it is repaired, it performs as a new one with the same probabilistic characteristics as originally. The bridge manager wants to carry out inspection plan but he is not sure whether or when to implement damage detection system. Assume the structural integrity management is performed at year 10 or 20 or 30 or 40 . The illustration of decision tree and quantification the value of information is presented in Figure 5 and Figure 6. The expected benefit and cost analysis according to [7] is shown in Table II. The probability of truss failure is calculated when both the coefficient correlation of resistance and damages equal to 0.5 .

It is observed from Figure 7 that the expected value of service life benefits first increase and slightly decrease at the late stage of service life, which can be explained with the increasing probability failure of system and decreasing accumulated benefit and costs due to discounting. The value of DDS will increase with time, which indicates that the 


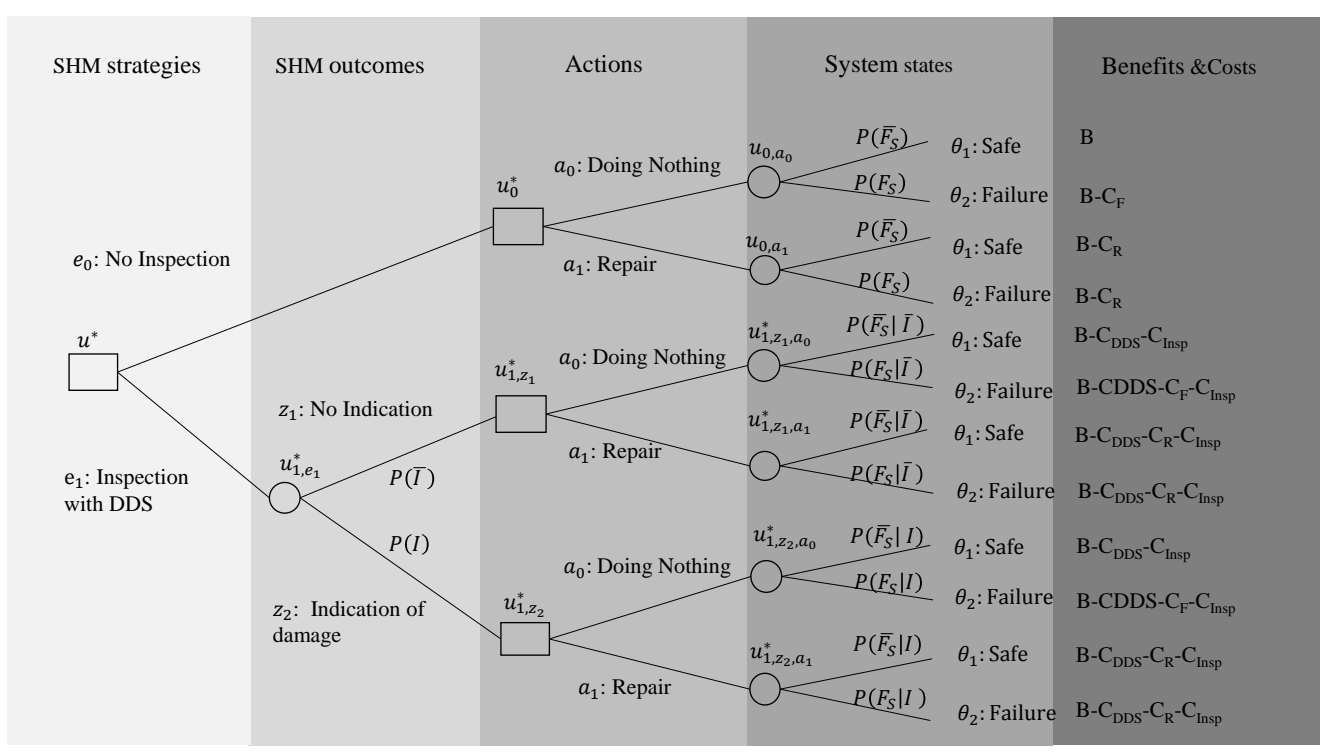

Figure 5. Illustration of decision tree and VoI

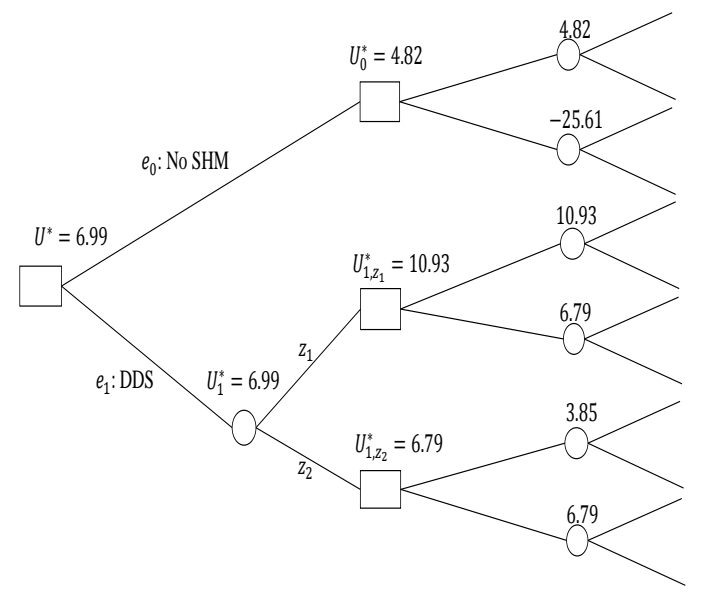

Figure 6. Documentation of decision analysis

$$
(t=\text { year } 40)
$$

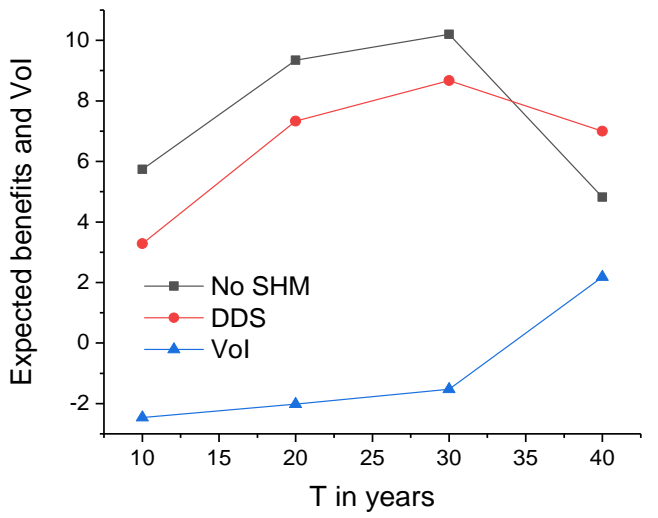

Figure 7. VoI in year 10, 20, 30 or 40

risks of system failure are significantly higher than the accumulated structural integrity management benefit and costs. It is beneficial to implement DDS system at late year of service life with high probability failure of the component/system when damages are easy to be detected.

\begin{tabular}{ccccccc}
\multicolumn{6}{c}{ TABLE II. PARAMETERS IN THE COST AND BENEFIT ANALYSIS } \\
\hline \multirow{2}{*}{ Variable } & Discount & Repair cost & Failure & Inspection & DDS cost & Annual benefit \\
& rate $r$ & $C_{R}$ & cost $C_{F}$ & $\operatorname{cost} C_{\text {Insp }}$ & $C_{D D S}$ & $B$ \\
Value & 0.02 & 10 & 100 & 1 & 2 & 0.7 \\
\hline
\end{tabular}

\section{CONCLUSION}

It has been demonstrated how the value of damage detection information can be quantified in the framework of the Bayesian decision theory and on the basis of the Value of Information. The quantification the value of damage detection information requires (1) damage detection performance models predicting the information in conjunc- 
tion with the structural performance and containing its precision and costs on structural system level, (2) actions to ensure the structural integrity and (3) the structural system performance and its risk and functionality throughout the service life. The example of a deteriorating Pratt truss system illustrates the quantification of the value of damage detection information. From the case study, at the late stage of service life with considerable damage causing a relatively high probability of failure, a high value of damage detection information is calculated. In earlier stages of the service life with a lower probability of system failure, the value of damage detection information DDS is negative.

\section{ACKNOWLEDGMENT}

The project INFRASTAR (infrastar.eu) has received funding from the European Union's Horizon 2020 research and innovation programme under the Marie SkłodowskaCurie grant agreement No 676139. The grant is gratefully acknowledged. Furthermore, the support of COST Action TU1402 on Quantifying the Value of Structural Health Monitoring is gratefully acknowledged.

\section{REFERENCES}

1. Döhler, M. and S. Thöns. 2016. "Efficient Structural System Reliability Updating with Subspace-Based Damage Detection Information," in EWSHM-8th European Workshop on Structural Health Monitoring.

2. Raiffa, H. and R. Schlaifer. "Applied Statistical Decision Theory. 1961," Division of Research, Harvard Business School, Boston, MA.

3. Pozzi, M., A. Der Kiureghian, and T. Kundu. 2011. "Assessing the value of information for long-term structural health monitoring," in Proc. of SPIE Vol, vol. 7984, pp. 79842W-1.

4. Thöns, S. 2011. Monitoring based condition assessment of offshore wind turbine support structures, Ph.D. thesis, ETH.

5. Thons, S. and M. H. Faber. 2013. "Assessing the value of structural health monitoring," Safety, Reliability, Risk and Life-cycle Performance of Structures and Infrastructures.

6. Faber, M. H. and S. Thöns. 2014. "On the value of structural health monitoring," Safety, Reliability and Risk Analysis.

7. Qin, J., S. Thöns, and M. H. Faber. 2015. "On the value of SHM in the context of service life integrity management," .

8. Döhler, M., L. Mevel, and F. Hille. 2014. "Subspace-based damage detection under changes in the ambient excitation statistics," Mechanical Systems and Signal Processing, 45(1):207224.

9. Döhler, M., L. Mevel, and Q. Zhang. 2016. "Fault detection, isolation and quantification from Gaussian residuals with application to structural damage diagnosis," Annual Reviews in Control, 42:244-256.

10. Hong, H. P. 1997. "Reliability analysis with nondestructive inspection," Structural Safety, 19(4):383-395.

11. Madsen, H. 1987. "Model updating in reliability theory," in Proc. ICASP, vol. 5, pp. 564577.

12. JCSS, P. 2006. "JCSS Probabilistic Model Code," Resistance models: Fatigue models for metallic structures. www: http://www. jcss. ethz. ch. 